\title{
Princípios de aprendizagem de jogos eletrônicos: gameficando a aula de línguas
}

\author{
Claudia Rodrigues Murta \\ Universidade Federal do Triângulo Mineiro/Cefores \\ claudiarodriguesmurta@gmail.com \\ Marcus Guilherme Pinto de Faria Valadares \\ Universidade Federal de Minas Gerais \\ marcus.valadares@gmail.com
}

\begin{abstract}
Resumo
O objetivo deste artigo é discutir a aprendizagem propiciada pela experiência com jogos eletrônicos e como professores e escolas poderiam aprender com os jogos que apresentam princípios epistêmicos (SHAFFER et al., 2004). E ainda, apresentar a análise, segundo os princípios de Gee $(2005 ; 2008)$, de nossa experiência em jogar um jogo comercial. Agameficação(DETERDING, 2011) é um processo que se vem disseminando como estratégia de aprendizagem. Esperamos com esta discussão despertar o interesse de professores para o potencial dos jogos eletrônicos na aprendizagem de línguas e demais conteúdos.
\end{abstract}

Palavras-chave: Jogos eletrônicos.Aprendizagem.Gameficação.

\begin{abstract}
The aim of this article is to discuss learning afforded by the experience of playing video games and how teachers and schools could learn from games that have epistemic principles (SHAFFER et al., 2004). We also present our experience in a commercial game, according to the principles of Gee (2005; 2008). The gamification (DETERDING, 2011) is a process that has been growing as a learning strategy. We hope that this discussion can draw teacher's attention to the potential of computer games for language learning and other contents.
\end{abstract}

Keywords: Video games.Learning.Gamification. 


\section{Introdução}

Presenciamos cotidianamente o impasse de escolas, professores e pais (entre outros) ante a celeridade da expansão e do ordenamento das Tecnologias de Informação e Comunicação (TICs), que parecem impactar profundamente as mais distintas esferas de nosso modus vivendi, sendo o contexto educacional uma delas. As novas e específicas habilidades que nos são demandadas pelos aparatos tecnológicos, que, fugazmente, surgem e se tornam obsoletos, são um desafio para os profissionais e as instituições de ensino, que precisam refletir diariamente sobre os novos questionamentos que emergem com relação às TICs e suas influências no processo de ensino/aprendizagem.

A ubiquidade das TICs em nosso cotidiano colocou-nos em um processo que Lankshear e Knobel (2003), citados por Mattos (2011), denominam de "princípio da irreversibilidade". Segundo os autores, todos os indivíduos, na posse ou não de uma ferramenta tecnológica, são afetados pelas mudanças provocadas por ela, pois a sociedade, de forma geral, utiliza e é transformada por essas ferramentas.

No momento em que os muros da escola se encontram abalados por outras fontes de informação que outrora eram exclusivas dela, torna-se necessário questionar as bases em que o processo de ensino/aprendizagem se estrutura. Segundo Moran (2007), o advento da internet começa a transformar a educação.

Outro grande ponto de transformação, necessário, mas caminhando a passos lentos, é a maneira com que a escola e seus profissionais trabalham com os alunos. A geração que as instituições escolares acolhem na contemporaneidade, nascida imersa neste mar de aparatos tecnológicos, é chamada por Prensky (2001; 2001a) de nativos digitais.

Conectados à rede mundial de computadores, os nativos digitais podem se autoletrar, e, por isso, requerem uma forma dinâmica, participativa, descentralizada, independente e autônoma de aprender, o que coloca em xeque as formas tradicionais de ensino/aprendizagem. Esses indivíduos ensinam e aprendem simultaneamente em um processo de compartilhamento no qual são tanto consumidores como produtores de informação. 
O professor, por sua vez, fala-nos Xavier (2005), também necessita de mudanças em sua prática pedagógica para acompanhar o sujeito da geração digital, como desenvolver habilidades de:

Pesquisador, não mais repetidor de informação; articulador do saber, não mais fornecedor único de conhecimento; gestor de aprendizagens, não mais instrutor de regras; consultor que sugere, não mais chefe autoritário que manda; motivador da "aprendizagem pela descoberta", não mais avaliador de informações empacotadas a serem assimiladas e reproduzidas pelo aluno. (XAVIER, 2005, p. 3)

Nesse contexto, em que o aluno não é concebido simplesmente como indivíduo passivo em relação ao conhecimento, temos de deixar claros alguns conceitos que, em continuidade às características de professores e alunos, são esclarecedores no processo ensino/aprendizagem na contemporaneidade. Vemos, então, a necessidade do formar (dar corpo ou forma; moldar; traçar; criar; estabelecer) perder espaço para o informar (dar informações a respeito de; avisar; dar parecer sobre); o treinar (cevar; adestrar; acostumar) transformar-se em educar(dar educação a; adquirir os dotes físicos, morais e intelectuais que dá a educação); o ensinar (instituir, dar lições a, indicar, educar) perder destaque para o aprender (ir adquirindo conhecimento de). ${ }^{1}$ Refletir sobre esses conceitos torna-se uma questão ainda mais cara para entendermos as mudanças de paradigma que atravessam a educação.

O que se percebe, no entanto, nos informaJenkins (2006), é o desconforto e a censura das instituições de ensino, dos professores e dos pais anteos avanços tecnológicos e o comportamento das crianças e dos adolescentes decorrente do contato com essas tecnologias, reprimindo as características inerentes à nova geração. $\mathrm{O}$ autor adverte-nos que a questão central das práticas midiáticas nas quais os jovens se envolvem não está ligada aos efeitos da mídia sobre esses indivíduos, mas à maneira como eles fazem uso da mídia. Inseridos no que o autor chama de cultura participativa, os indivíduos

${ }^{1}$ http://en.wikipedia.org/wiki/Ice_Age_(franchise) 
transformam consumo em produção, leitura em escrita, cultura do espectador em cultura participativa.

Como nos mostra Paiva (2006), a história do ensino de línguas sempre foi acompanhada pelas inovações tecnológicas, que desempenham o papel de mediadoras na aproximação entre aprendizes e nativos e propiciam novas oportunidades de contato com a língua alvo. Em outras palavras, os artefatos culturais incrementam a exposição à língua para além do contexto escolar.

Nesse contexto, vemos os jogos, antes restritos aos videogames, presentes agora nos computadores, nos tablets e também nos telefones celulares, passarem a fazer parte da realidade cotidiana das pessoas que estão conectadas à internet. Os jogos, mais que entretenimento, passam a mobilizar esforços e a criar comunidades que se relacionam a objetivos comuns, concebendo novos mundos sociais e culturais. Autores como Gee (2000; 2005; 2007; 2008), Prensky (2001), Escheverria (2011), Deterding (2011), Shaffer et al. (2004), só para citar alguns, acreditam que os jogos eletrônicos desenvolvem as habilidades cognitivas dos jogadores porque são feitos com base em princípios bem estruturados de jogabilidade e de aprendizagem, e que as escolas poderiam beneficiar-se muito aprendendo com os designers de jogos "maneiras de aprender na nova era da informação" (SHAFFER et al., 2004, p. 3). ${ }^{2}$

O objetivo deste trabalho é discutira aprendizagem propiciada pela experiência com jogos eletrônicos e como professores e escolas poderiam aprender com os "bons jogos", nas palavras de Gee (2005). A gameficação (DETERDING, 2011) é um processo que se vem disseminando como estratégia de aprendizagem no mundo corporativo, nos negócios, mas ainda está apenas timidamente presente nas escolas. Esperamos com esta discussão despertar o interesse de professores para o potencial dos jogos eletrônicos na aprendizagem.

${ }^{2}$ Esta e demais traduções são de nossa responsabilidade. 


\section{O que os videogames nos podem ensinar?}

Por muito tempo, e ainda hoje, é comum pais e professores advogarem contra os jogos eletrônicos, alegando que eles podem motivar a violência entre os jovens. E realmente sabemos que alguns videogames incitam a violência gratuita e atitudes racistas, sexistas, entre outras barbaridades. No entanto, os jogos podem ter um potencial pedagógico desconhecido pelo senso comum.

Pesquisas sobre a relação entre jogos eletrônicos e videogames e educação não são tão recentes. Mitchell e Savill-Smith (2004) citam alguns trabalhos que datam da década de 1990, como os de Randel et al. (1992), Dempsey,Rasmussen e Lucasse (1994) eEmes (1997), que encontram diferenças no uso dos jogos, dependendo da área educacional em que são usados. As pesquisas dos estudiosos citados relatam que os jogos são mais usados com sucesso na matemática, na física e na linguagem.

Neste trabalho, tomaremos como principal referencial teórico as pesquisas deJames Paul Gee, professor da Universidade do Arizona nos Estados Unidos, considerado um especialista e defensor do uso dos videogames na educação. Ele tem dedicado atenção aos aspectos positivos, dos "bons videogames", aqueles que apresentam alguns princípios baseados na ciência da cognição e são desenvolvidos por designers que perceberam o que o jogo deve ter para despertar interesse e habilidades. Gee (2008) afirma que a aprendizagem é guiada e organizada por princípios empiricamente confirmados por pesquisas, como as de Bransford, Brown e Cocking (2000); Shaffer(2004) e Sawyer (2007), entre outros,e que não é por acaso que os jogos envolvem tanto os jogadores, criando comunidades, e também os milhões que a indústria do entretenimento investe e arrecada com a venda desses artefatos.

Em um trabalho desenvolvido com Shafferet al (2004) afirmam que os videogames são atividades significativas, experienciais, sociais e epistemológicas. Os videogames integram pensamento, interação social e tecnologia. Ao participar de práticas sociais, os jogadores têm oportunidade de explorar novas identidades. Os jogos encorajam a exploração, a construção personalizada de significados, a expressão individualizada e a experimentação lúdica com fronteiras sociais. Além disso, propiciam a liberdade de criar sua 
própria trajetória de aprendizagem (SHAFFER et al., 2004). Nesse trabalho, os pesquisadores discorrem sobre o que eles denominam de epistemic frame e epistemic games. Epistemic frame, que poderíamos traduzir como quadro epistêmico,diz respeito ao fato de os jogos poderem levar as pessoas a pensar e a agir de maneira semelhante, a desenvolver uma cultura local, do grupo, ao se congregarem comunidades que têm os mesmos interesses, objetivos, habilidades, identidades, em "comunidades de prática" (LAVE; WENGER, 1991). Dessa forma, o conhecimento produzido nessa cultura passa a ser distribuído entre a comunidade e o ambiente do jogo. A participação na comunidade passa a significar aprendizagem quando o jogador passa da condição de participante periférico, iniciante, a participante pleno, experiente (LAVE; WEGER, 1991). Esse tipo de aprendizagem é o que esses autores denominam de aprendizagem situada: o aprendiz aprende fazendo, vivendo as possibilidades propiciadas pela cultura e pelo ambiente, nesse caso, o jogo. Shaffer et al. (2004) afirmam que o potencial dos videogames e o futuro da aprendizagem está no desenvolvimento do que chamam de epistemic games, jogos que estimulam os jogadores a participar em comunidades de prática, a atuar nos mundos criados, o que torna possível uma compreensão situada, uma efetiva participação social, mostrando identidades, valores e modos de pensar importantes para a comunidade. Os autores nesse trabalho propõem que os epistemic games podem ser uma ferramenta de ensino para a escola, ao adotar um novo modelo de ensino, uma nova epistemologia, que seja mais compatível com a organização social e "as realidades da vida pós-industrial, da sociedade global, de alta tecnologia" (SIZER, 1984 apud SHAFFER et al., 2004, p. 17).

No sentido de delinear ideias mais claras acerca da aprendizagem propiciada pelos jogos, Gee (2008) estabelece algumas condições para que a experiência seja transformada em aprendizado, são elas:

1) a experiência pode ser usada para resolver problemas futuros se ela for estruturada por objetivos específicos;

2) as experiências precisam ser interpretadas, ou seja, é preciso pensar na ação e depois da ação em como os objetivos se relacionam com o novo raciocínio na nova situação. Isso significa tirar lições e antecipar-se para saber onde essas lições podem ser usadas;

3) as pessoas aprendem melhor quando têm feedback 
imediato durante suas experiências, pois elas podem identificar e avaliar seus erros;

4) os aprendizes precisam de amplas oportunidades para aplicar suas experiências prévias e simular as novas situações;

5) os alunos precisam aprender a interpretar suas experiências e explicá-las para outras pessoas, seus pares ou especialistas, pois isso é uma boa forma de aprender. A interação social, a discussão, a apresentação são importantes.

Em outro texto famoso de Gee (2005), Goodvideogames goodlearning, o pesquisador apresenta alguns princípios de aprendizagem que os jogos incorporam e que a escola deveria incorporar também para que a aprendizagem dos conteúdos fosse mais efetiva. Apresentaremos os 16 princípios de aprendizagem de James Paul Gee (2005), os quais transcrevemos a seguir.

1) Identidade: aprender requer que o aprendiz assuma uma nova identidade, comprometa-se com o mundo no qual irá atuar, tome um personagem ou construa um novo. Geeindaga-se por que a identidade de ver e fazer ciência deveria ser diferente, menos atrativa.

2) Interação: em um bom jogo, as palavras são colocadas em contexto, em uma relação interativa do jogador com o mundo. Então, também na escola os textos devem ser colocados em contexto de interação na qual mundo e pessoas possam estabelecer uma relação responsiva.

3) Produção: jogadores são produtores, não apenas consumidores, são escritores, não apenas leitores. Os jogadores ajudam a escrever o mundo do jogo em que eles vivem. Na escola, os alunos poderiam ajudar a escrever o currículo que eles estudam.

4) Assumir riscos: os jogadores são encorajados a assumir riscos, a explorar e testar novidades. Num jogo, perder pode ser produtivo. As escolas pouco permitem riscos e falhas.

5) Customização: os jogadores podemcustomizar o jogo para que ele se adéque ao estilo de jogar e aprender de cada um. Jogos têm geralmente diferentes níveis de dificuldade e permitem que os jogadores resolvam os problemas de diferentes maneiras. Currículos customizados na escola não seriam apenas sobre criar seu próprio caminho, mas sobre reais interseções entre o currículo, os interesses, os desejos e os estilos de aprender.

6) Agência: os jogadores sentem o sentido real de 
gerenciamento e controle,bem mais raros na escola.

7) Problemas exequíveis: pesquisas mostram que quando os aprendizes são deixados em um espaço permissivo eles tendem a criar soluções criativas para problemas complexos, mas soluções que não levam a boas hipóteses de como resolver mais tarde problemas mais simples. Em um bom jogo, problemas que os jogadores enfrentam são ordenados para que eles criem hipóteses que depois vão funcionar bem em problemas mais difíceis. É importante como o problema é organizado - esta é a razão de os jogos terem níveis.

8) Desafio e consolidação: bons jogos oferecem aos jogadores uma quantidade de problemas desafiadores e deixam que eles resolvam esses problemas até que tenham virtualmente rotinizado e automatizado suas soluções. Só assim os jogadoressão desafiados a resolver umnovo problema para que integrem essa nova aprendizagem à sua experiência. A maestria na solução do problema é consolidada por meio da repetição com variações. Esse ciclo tem sido chamado de "ciclo de expertise". Na escola, algumas vezes os estudantes mais fracos não têm oportunidades suficientes para consolidar sua aprendizagem, e os bons estudantes não têm desafios reais suficientes para sua maestria escolar.

9) Just in time e on demand: "a tempo" e "sob demanda".Em jogos, as informações verbais são dadas no momento em que os jogadores precisam usá-las ou de antemão, para tê-las quando precisarem. A informação deveria ser usada do mesmo jeito na escola.

10) Significado situado: pesquisas recentes sugerem que as pessoas só sabem realmente o que uma palavra significa e aprendem novas quando conseguem ligar essas palavras a certas experiências, ou seja, a certas imagens, diálogos, sons com os quais a palavra se relaciona. As palavras têm significado situado em diferentes contextos de uso. Jogos sempre situam significados. A escola também deveria fazer isso.

11) Agradavelmente frustrante: bons jogos são desafiadores e factíveis ao mesmo tempo, e isso é altamente motivador para os aprendizes. A escola geralmente é muito difícil para alguns estudantes e entediante para outros.

12) Sistema de pensamento: jogos encorajam jogadores a pensar sob a forma de relações, não sob eventos isolados, fatos e 
habilidades. Em um mundo complexo, mundo global, tal maneira de pensar é crucial.

13) Explore, pense lateralmente, repense objetivos: os jogos encorajam os jogadores a explorar tudo antes de tomar decisões. Pensar lateralmente, e não só linearmente, é usar tal exploração e pensamento lateral para reconquistar os objetivos de tempos em tempos.

\section{4) Ferramentas inteligentese conhecimento}

distribuído: os jogos possuem ferramentas inteligentes que ajudam o jogador nas jogadas. O conhecimento é distribuído entre os jogadores, cada jogador contribui com uma habilidade distinta. Ferramentas inteligentes e o conhecimento distribuído são a chave para os locais de trabalho atuais, mas nem sempre para as escolas.

15) Times multifuncionais: em jogos de múltiplos jogadores, cada jogador tem uma habilidade diferente. Cada jogador deve dominar sua própria função, mas ter entendimento suficiente das especialidades dos outros para colaborarem e funcionarem juntos. As pessoas se unem em razão de esforços comuns, e não por causa de sua raça, classe ou gênero. Tais afiliações são demandadas no trabalho moderno, mas nem sempre nas escolas modernas.

16) Desempenho antes de competência: bons videogames operam por um princípio contrário ao da maioria das escolas: desempenho antes de competência. Jogadores podem exercitar antes de serem competentes, apoiados pelo design do jogo e por ferramentas inteligentes que o jogo oferece ou ainda por jogadores mais experientes. É assim que se processa a aquisição da linguagem, mas nem sempre as escolas agem dessa forma. Geralmente elas orientam que os estudantes ganhem competência na leitura de textos antes que possam exercitar seu desempenho no domínio do que estão aprendendo.

Todos esses princípios apresentados por Gee (2005) poderiam ser aplicados nas escolas, o que tornaria o aprendizado mais instigante, interessante e significativo. $\mathrm{O}$ autor, no final desse estudo, afirma que ele não está dizendo para se usar jogos nas escolas nem que eles sejam a solução dos problemas de aprendizagem, mas que devemos pensar em como promover uma aprendizagem dentro ou fora da escola, usando ou não jogos, pensando nos princípios de aprendizagem presentes nos bons jogos para que isso leve a uma 
aprendizagem reflexiva e estratégica.

No trabalho What video games have to teach us about learning and literacy, de 2007, James Paul Gee discorre sobre outros princípios, totalizando 36, que podem ser utilizados na educação, relacionando esses princípios ao design dos jogos e a elementos da semiótica importantes para o desenvolvimento das habilidades cognitivas e perceptuais dos jogadores e de alunos. Não discutiremos cada um desses 36 princípios, pois vários deles se relacionam com os princípios já descritos e são facilmente inferíveis. Mas os agrupamos em algumas categorias que podem facilitar o entendimento, são elas:

a) Aprendizagem e domínio semiótico: agrupam-se nesta categoria os seguintes princípios: 1) da aprendizagem crítica e ativa; 2) do planejamento; 3 ) semiótico; 4) dos domínios da semiótica; 5) do domínio semiótico sobre o pensamento metanível.

b) Aprendizagem e identidade: nesta categoria estão os princípios 6) da moratória psicossocial; 7) da aprendizagem comprometida;8) da identidade; 9) do autoconhecimento; 10) da ampliação do Princípio de Input; 11) do resultado/da conquista.

c) Significado situado e aprendizagem: nesta categoria estão os princípios 12) da prática; 13) da aprendizagem contínua; 14) do regime da competência;15) da provação; 16)das múltiplas rotas; 17) do sentido situado; 18) textual; 19) intertextual;20)multimodal; 21) da inteligência material; 22) do conhecimento intuitivo.

d) Transferência de conhecimento: agrupam-se nesta categoria os princípios 23) do subconjunto; 24) incremental; 25) da amostra concentrada; 26) das habilidades básicas de baixo para cima; 27) da informação explícita porondemand e just in time; 28) da descoberta; 29) da transferência.

e) Modelo cultural: nesta categoria estão os princípios 30) modelos culturais sobre o princípio mundial; 31) modelos culturais sobre o princípio da aprendizagem; 32) modelos culturais sobre o princípio dos domínios semióticos.

f) Aprendizagem como atividade social: por último, os princípios 33) da distribuição; 34) da dispersão; 35) do grupo de afinidade; 36) do pertencimento.

A exposição desses princípios é importante, pois pode nos levar a pensar mais sistematicamente nos designs que implementamos em nossas aulas.Mesmo que não utilizemos jogos para motivar a 
aprendizagem em nossas disciplinas, esses princípios podem servir como referenciais para a promoção de atividades que levem a uma aprendizagem mais efetiva. Pensamos que isso não deve ser tomado como um receituário, muito pelo contrário, mas como problematizações que podem fundamentar nossas reflexões sobre nossas realidades.

O processo de gameficação, como tem sido chamado em várias áreas do conhecimento -tais como negócios, administração, economia, engenharias -, mostra-se como uma alternativa de engajamento em atividades de construção de conhecimento por meio de estratégias de jogo, e isso tem chamado a atenção dos estudiosos (DETERDING, 2011). Gameficação é um termo novo que tem origem na indústria da mídia digital.Sua primeira documentação data de 2002, quando foi cunhado pelo programador e pesquisador britânico Nick Pelling, mas sua adoção só ganhou notoriedade em meados de 2010, após seu uso pela game designer Jane Mcgonial em uma apresentação de TED. No entanto, a estratégia de usar mecanismos de jogos para resolver problemas não é coisa nova. Os jogos estão enraizados nas mais diversas culturas, servindo, ao longo da história, como importante estruturador social das comunidades. A gameficaçãoé a conscientização do interesse das pessoas pelos jogos(VIANNA et al., 2013).

A gameficação tem sido tomada como a adoção da tecnologia dos jogos para além de seu ambiente. O termo, portanto, refere-se ao uso do design, dos elementos edas características dos jogos em contextos de nãojogos com o intuito de oferecer novos caminhos aos métodos tradicionais de encorajamento de mudanças de comportamento, familiarização com novas tecnologias, aceleração dos processos de aprendizagem e de treinamentos e a facilitação de tarefas complexas, tediosas e repetitivas. (VIANNA et al., 2013). Assim, várias áreas vêm tentando capitalizar as características positivas dos jogos para sua utilização em seus próprios espaços, servindo como affordances ${ }^{3}$ motivacionais.

${ }^{3}$ De acordo com Gibson (1986), o termo affordance refere-se ao o que "o ambiente fornece ao animal (no nosso caso, ser humano), tanto positivamente quanto negativamente, implicando complementaridade do animal e do ambiente" (SOUZA, 2011, p.4). Para Van Lier (2002), a linguagem é parte da 
Vianna et al. (2013, p. 19),ao tratarem dagameficaçãoaplicada ao mundo dos negócios,revelam-nos que antes de esta ser aplicada deve ser planejada segundo três perguntas norteadoras, a saber: por que um jogo irá beneficiar determinado usuário? Quais os objetivos por trás do jogo? Como os mecanismos do jogo vão fazer com que o usuário atinja os objetivos estabelecidos?

Os mecanismos dos jogos, em outras palavras, os componentes utilizados para recompensar e, assim, estimular os usuários são, dentre uma gama de ações, divididos segundo cinco elementos: status, acesso, influência, brindes e giftings. Esses componentes devem ser planejados de forma cautelosa para não serem, por um lado, inalcançáveis ou, por outro, banalizados. Nesse ponto, o estabelecimento de regras e feedback é importante para garantir o engajamento dos sujeitos no percurso da atividade(VIANNA et al., 2013).

O status é a forma mais explícita de se distribuir recompensas, podendo ser feito por meio dosrankingsdos participantes, distribuição de pontos ou premiações que destaquem os jogadoresperante os demais. A notoriedade em relação aos outros participantes, ou seja,o reconhecimento público, é considerada o elemento mais forte dentre os cinco.

O acesso é outro ponto estimulador nos sistemas de recompensa para engajar os participantes em seus objetivos. A possibilidade de entrada em um ambiente, a permissão de uso de alguns recursos privilegiados, etc. ou a negação desses recursos servem para impulsionar os sujeitos no alcance das próximas etapas.

A influência pode ser concedida aos jogadores de forma direta ou indireta. A primeira permite que o usuário tenha a sensação de controle no jogo, podendo ser concedida a ele por meio de algum benefício ou conquista durante o jogo. A segunda acontece quando um jogador tem a possibilidade de interferir positiva ou negativamente, voluntária ou involuntariamente no andamento de outrem.

Por último, os brindes e os giftings. Os primeirosseriam a forma mais simples de se recompensar, fornecendo itens, pistas, vidas,

ação e o "participante ativamente engajado recebe uma miríade de oportunidades para ação e interação significativas, e essas oportunidades são nomeadas affordances"., 
caracterizando-se como uma forma de feedback positivo. Os giftings, por sua vez, são uma forma de brinde concedida por outros jogadores na forma de troca de benefícios, fazendo com que os jogadores estabeleçam elos na criação de comunidades mais duradouras.

Apesar de ser uma tendência no "mercado" da educação, especialmente a privada, os jogos ainda não têm espaço garantido nas escolas públicas brasileiras,o que não pode ser admitido, visto que a escola, como espaço de promoção de letramentos, deve ser um lugar que aceita e promove novas formas de aprender, que reconhece as muitas vozes trazidas pelos alunos para a sala de aula, os muitos lugares, culturas, meios de se produzir conhecimento. A escola deve promover o ensino que leve em conta serem os aprendizes produtores de significados, agentes, participantes e cidadãos ativos que usam o letramento como uma ferramenta que permite um maior controle sobre os caminhos que o significado toma em suas vidas (COPE; KALANTZIS, 2012). Por sua vez, o papel do professor é o de articulador de sentidos, que promove a colaboração e a agência ${ }^{4}$ de seus alunos por meio de práticas problematizadoras da realidade local e global; os jogos, como artefatos naturalizados no cotidiano da geração de alunos atuais, devem ser conhecidos e reconhecidos pelos professores como um instrumento de aprendizagem.

A seguir, apresentamos a análise da nossa experiência de jogar um jogo eletrônico de uma franquia mundialmente conhecida a fim de verificar se e quais os princípios dos "bons jogos" de James Paul Gee estão presentes nesse jogo.

\section{Experienciando os princípios dos good games}

Pensando nos jogos como um ambiente autêntico em que as experiências dos jogadores podem ser transformadas em aprendizagem, selecionamos o jogo Ice Age Village como objeto de

\footnotetext{
${ }^{4}$ Agência é a vontade e a capacidade do indivíduo de agir. O termo envolve a complexa, dinâmica e multidimensional interação de causalidade que se estabelece entre indivíduo e os diversos segmentos da sociedade (MERCER, 2011).
} 
nossa análise, tendo como referência os princípios e as condições apresentados por Gee $(2005 ; 2008)$. Essa escolha é subsidiada no fato de comungarmos da idéia de Gee (2005) de que só podemos formar uma opinião sobre os jogos experienciando o jogo, jogando.

$\mathrm{O}$ game Ice Age Village faz parte da franquia multimidiáticalce Age (Era do Gelo), que possui investimentos em filmes de longa e curta metragem, um especial para televisão, uma peça de teatro, trilhas sonoras e jogos. Todos esses produtos estão ligados à história de um grupo de mamíferos que tenta sobreviver à Era do Gelo Paleolítico. ${ }^{5}$ Como o nome nos revela, o jogo trata da aventura do grupo que protagoniza os filmes da série na construção de uma aldeia para refugiar animais desamparados.

A base lógica por trás do jogo está ligada à questão do gerenciamento de recursos. Em outras palavras, o objetivo central do jogo é gerir todas as possibilidades disponíveis para o crescimento ou o bom andamento da vila. O objetivo do jogo já satisfaz a primeira e a segunda condições necessárias apresentadas por Gee (2008), que são a resolução de problemas por meio de objetivos específicos - manter a sustentabilidade da vila gerindo seus recursos -e a antecipação de ações relacionando os objetivos às vantagens que o jogador pode obter para si e para a vila. Essas condições desenvolvem no jogador um raciocínio em rede, pois ele terá de analisar cada jogada e sua relação com as demais, não em uma ação imediatista, mas pensada em termos de provisões futuras. Isso tem a ver também com um dos princípios apontados por Gee (2005) presentes nos bons jogos, que é pensar lateralmente, encorajar os jogadores a explorar tudo antes de tomar decisões. Um bom exemplo desse gerenciamento de pensamento é a economia das nozes. A fruta é um dos elementos mais preciosos do jogo. Elas podem desbloquear itens importantes, mas aparecem com pouca frequência. $\mathrm{O}$ jogador, impelido a cumprir metas e tarefas, deve saber avaliar qual o melhor momento de usar os recursos. Dessa forma, o jogador estará desenvolvendo outro princípio elencado por Gee (2005), o $12^{\circ}$, que é desenvolver um sistema de pensamento no qual os jogadores são encorajados a pensar sob a forma de relações, não sob eventos isolados, fatos e habilidades. E em um mundo globalizado, tal

${ }^{5}$ As informações relativas às palavras foram retiradas do dicionário Priberam. Disponível em: <http://www.priberam.pt/>. 
maneira de pensar é crucial.

O jogador é desafiado, portanto, a conjugar os gastos dos bens disponíveis com o crescimento da vila e o bem-estar dos animais, administrando o que pode ser usado, as metas a serem atingidas, as necessidades dos animais e a possibilidade de captar mais recursos. Tudo isso explora a criatividade, desenvolve o altruísmo e a agênciado jogador, nada lhe é dado pronto, ele terá de tomar decisões sobre quais alternativas serão melhores para a sobrevivência da coletividade.

Aexemplo de um jogo comercial, existe a possibilidade de se comprar, com moeda verdadeira, recursos para avançar e obter vantagens no jogo. No entanto, o jogador que opta por este caminho foge dos desafios propostos, seguindo um caminho mais confortável, e pode gastar bastante dinheiro.

$\mathrm{O}$ jogador deve prestar atenção nas possibilidades à sua frente. Muitas são as maneiras de se conseguir recursos. A melhor forma de se preparar para obter o melhor rendimento é ficar atento às frequentes dicas que aparecem por escrito. Essas dicas cumprem o princípio dos bons jogos, que Gee (2005) chama de "just in time" e "on demand", ou seja, nesses jogos, as informações verbais são dadas no momento em que os jogadores precisam usá-las. O jogador deve ficar atento para usar as dicas a seu favor e da coletividade, sem a necessidade de memorizar jogadas ou regras.

Um fator importante no jogo, foco deste trabalho, é que as dicas e todas as demais informações sobre ele são disponibilizadas em 11 idiomas distintos. O jogador pode escolher e, sempre que desejar, mudar o idioma para o de sua preferência. No caso de uma língua estrangeira, o contexto cheio de imagens, o texto escrito e o conhecimento prévio, fruto do caráter multimidiático da história, promovem um ambiente autêntico e rico para o aprendizado da língua alvo. Portanto, o jogo Ice Age Village pode ser uma ferramenta de aprendizagem de língua inglesa, ou de qualquer outra dos 11 idiomas disponíveis, interessante para se trabalhar na sala de aula e fora dela. A língua, como sabemos, é o instrumento de mediação social por excelência, e no jogo ela também tem papel fundamental, visto que as informações, as jogadas, as dicas e demais interações são feitas por meio da linguagem verbal escrita. Essa prática possibilita a aprendizagem da língua em contexto situado, o que também é um dos princípios de aprendizagem exposto pelo autor. Essa abordagem de 
ensino contempla o que preconiza Gee (2000, p. 4) sobre os novos estudos do letramento, que é se engajar em práticas sociais de linguagem diversas.

Outro elemento importante no Ice Age Village é a ideia de comunidade representada pela questão das famílias e dos amigos do vilarejo. Esse aspecto cria um ambiente de colaboração, conectividade e interdependência. Ademais dos gestos sociais que o jogo propõe pela necessidade de criar um ambiente confortável para as personagens, há também momentos colaborativos, de interação para além da vila, em que o participante pode entrar nos vilarejos de outros jogadores para buscar recompensas e crescimento próprio, como também ajudar na construção dos vilarejos dos vizinhos. Cada visita às vilas dos amigos pode gerar benefícios mútuos. Essa ideia é apresentada por Gee (2005) como times multifuncionais, ou seja, os bons jogos criam comunidades de múltiplos jogadores nas quais cada jogador tem uma habilidade diferente e troca ideias por meio da interação com outros jogadores no intuito de aperfeiçoar o jogo e as jogadas.

O jogador pode também convidar amigos de redes sociais, como o Facebook, e da Gameloft LIVE para jogar e interagir. Quanto mais jogadores adicionados a sua lista, mais amigos podem proporcionar moedas, nozes e pontos, itens que dão ao jogador poder de compra no jogo. Além da visita às vilas vizinhas, o ambiente promove links externos para fora da aldeia com jogos à parte e pequenos filmes. Esse ponto remete-nos à ideia de cultura da convergência proposta por Jenkins (2009), que representa a união de diversos consumidores-fruidores-produtores de artefatos culturais disponibilizados pelos canais de distribuição da cultura de massa transmidiáticos, que são aqueles que não se limitam a um único meio de transmissão-apreensão.Esses canais envolvem esses consumidoresfruidores-produtores em um universo coletivo de compreensão e experiências diversas que transcendem a apreensão passiva de um único indivíduo.

Jenkins (2009) afirma que novas estruturas narrativas estão surgindo para fundamentar as experiências e os conhecimentos de uma sociedade fragmentada e multicultural e que essas narrativas seriam compartilhadas em multimeios, e em cada um deles o consumidor teria a possibilidade de experienciar uma faceta ou aprofundar seu conhecimento em relação à franquia explorada. 
Os elementos apresentados no jogo Ice Age Village caracterizam-no como um "bom jogo" que pode propiciar uma "boa aprendizagem" ao estudante de língua estrangeira, visto que desenvolve habilidades sociointerativas, cognitivas e linguísticas.

\section{Considerações finais}

A gameficação é um caminho para o engajamento e a motivação dos alunos na aprendizagem de qualquer natureza e de língua em particular. Vivemos um momento no qual o desinteresse em relação à escola se mostra alarmante. Acreditamos que esse desinteresse seja reflexo de um modelo de escola que não mais atende às expectativas dos nativos digitais (PRENSKY, 2001) e não condiz com o mundo hipermidiático em que vivemos. Os jogos podem ser uma alternativa para o ensino e a aprendizagem, visto que quando bem construídos podem desenvolver no aluno habilidades multifuncionais e interdisciplinares necessárias ao contexto atual.

A interação intensa dessas crianças e jovens com os artefatos digitais parece impactar a forma como eles processam a informação e constroem o conhecimento, e a escola não pode ficar alheia a isso. Como atesta Carr (2010),parece que a tecnologia vem mudando nossos cérebros. Apesar de ainda ser cedo para termos uma visão clara dessa afirmação, percebemos mudanças significativas em relação à atenção, à concentração, às habilidades motoras, ao raciocínio, etc. em nossos alunos. Nas palavras de Prensky (2001), os nativos digitais são "falantes nativos" da linguagem digital dos computadores, dos videogames e da internet, e esse universo familiar chama mais atenção do que o conteúdo "analógico" do quadro e do giz. Os nativos digitais estão acostumados a receber informações muito rapidamente.

Os videogames fazem parte da realidade dessa geração que busca a instantaneidade. Os jogos são importantes porque apresentam aos jogadores mundos simulados que, se bem construídos, não dizem respeito somente a fatos ou habilidades isoladas, mas incorporam práticas sociais particulares. Os jogadores participam de comunidades de prática e desenvolvem modos de pensar que organizam essas práticas. 
Devemos mudar nossa perspectiva em relação aos jogos como artefatos de "mero entretenimento". Os videogames são importantes porque motivam as pessoas a participar de mundos novos. Levam os jogadores a pensar, falar e agir, a desempenhar papéis que seriam inacessíveis no mundo real. Nos mundos virtuais, os aprendizes experimentam as realidades concretas que as palavras e os símbolos descrevem desenvolvendo uma compreensão situada. Os mundos virtuais dos jogos podem desenvolver um conjunto de práticas sociais efetivas. Participando dessas práticas sociais, os jogadores têm a oportunidade de explorar novas identidades, desenvolver valores compartilhados, integrar o saber com o fazer.

Para construir jogos com os princípios como os que Gee (2008) menciona é preciso conhecer como os praticantes desenvolvem suas formas de pensar e agir. Essa compreensão origina-sepor meio de epistemografias de prática: estudos etnográficos detalhados de como a estrutura epistêmica de uma comunidade de prática é desenvolvida por seus membros (SHAFFER et all., 2004).

Nesse sentido, os professores devem engajar-se em comunidades de prática de jogos para entender o funcionamento desses games, até para poder orientar seus alunos na prática consciente desses jogos, e ainda para aproveitar o potencial dos jogos em suas disciplinas. No ensino de línguas, o potencial dos jogos é evidente, pois o jogador interage com os outros jogadores e com a máquina por meio de linguagens. Em grande medida, as comunidades de prática que se formam a partir da experiência dos jogos são multilingues, o que pode ser desafiador e motivador para os alunos quererem aprender uma segunda língua.

Embora os jogos estejam despertando o interesse de pesquisadores e professores, eles sozinhos não farão nada pela escola e pela aprendizagem. Nada substituirá a abordagem metodológica do professor, os objetivos pedagógicos de formação e de construção do conhecimento. Podemos sim aproveitar o potencial dos jogos para a aprendizagem, mas aliar metodologia com tecnologia para desenvolver uma aprendizagem situada capaz de ampliar em nossos alunos mais do que habilidades técnicas, fomentar capacidades cognitivas, afetivas, comunicacionais para que eles enfrentem esse mundo em constante transformação. 


\section{Referências}

BRANSFORD, JohnD.; BROWN, Ann Leslie; COCKING, Rodney. How people learn: brain, mind, experience and school. Washington, D.C.: National Academy Press, 2000. p. 206-230.

CARR, Nicholas. What the internet is doing to our brains: the shallows. New York:Norton \& Company, 2010.

COPE, B. Cope; KALANTZIS, Mary. Critical literacies pedagogy. Literacies. Cambridge University Press, 2012.

DEMPSEY, John V.; RASMUSSEN, Kathleen; LUCASSEN, Elisabeth B. Instructional gaming: implications for instructional technology. Paper presented at the Annual Meeting of the Association for Educational Communications and Technology, Nashville, TN, p. 16-20, Feb. 1994.

DETERDING, Sebastian. From game design to gamefulness: defining "gamification". Mindtrek'11, Tampere, Finland, 2011.

EMES, Craig. E. Is Mr. Pac Man eating our children? A review of the effect of video games on children. Canadian Journal of Psychiatry,n.42, p. 409-414,1997.

ESCHEVERRIA, Alejandro. et al. A framework for the design and integration of collaborative classroom games. Computers \& Education, v. 57, n. 1, p. 1127-1136,2011.

GEE, James Paul. New literacy studies. Situated literacies: reading and writing in contex. London: Routledge, 2000.

85, n. 2,2005 .

. What video games have to teach us about learning and

literacy.New York:Palgrave Macmillan, 2007. 
Princípios de aprendizagem de jogos eletrônicos...

- Learning and games. The ecology of games: connecting youth, games and learning. MacArthur Foundation Series on Digital Media and Learning. Cambridge, MA: The Mit Press, 2008.

JENKINS, Henry. Fans, bloggers, and games: exploring participatory culture. New York: New York University Press, 2006.

- Cultura da convergência: a colisão entre os velhos e os novos meios de comunicação.Tradução: Susana Alexandria. 2.ed. São Paulo: Aleph, 2009.

LANKSHEAR, Colin.; KNOBEL, Michele. New literacies: changing knowledge and classroom learning.

Buckingham: Open University Press, 2003.

LAVE, Jean; WENGER, Étienne. Situated learning: legitimate peripheral participation. Cambridge: Cambridge University Press, 1991.

MATTOS, Andrea. M. Novos letramentos, ensino de língua estrangeira e o papel da escola pública no século XXI. Revista X, v. 1, p. 33-47, 2011.

MERCER, Sarah. Understanding learner agency as a complex dynamic system. System, v. 39, n. 4, p. 427-436, 2011.

MITCHELL, Alice.;SAVILL-SMITH, Carol. The use of computer and video games for learning: a review of the literature. Learning andSkillsDevelopmentAgency, 2004.

MORAN, José Manuel. A educação que desejamos, novos desafios e como chegar lá. Campinas: Papirus, 2007.

PAIVA, Vera.Lucia.M.O. O uso da tecnologia no ensino de línguas estrangeiras: breve retrospectiva histórica. In: $7^{\circ}$ Encontro do Celsul (Centro de Estudos Linguísticos do Sul), 2006, Pelotas. Programação e resumos. Santa Maria: Gráfica Editora Pallotti, 2006. p. 1-16. 
PRENSKY, Marc. Digital natives, digital immigrants Part 1. On the Horizon, v. 9, n. 5, p. 1-6, 2001.

- Digital natives, digital immigrants. Part 2: Do they really think differently? On the Horizon, v. 9, n.6, p. 1-6, $2001 \mathrm{a}$.

RANDEL, Josephine.et al. The effectiveness of games for educational purposes: a review of recent research. Simulation \& Gaming, v.23, n. 3, set. 1992.

SAWYER, David B. The "Serious Games" Landscape. Presented at the Instructional \& Research Technology Symposium for Arts, Humanities and Social Sciences. Camden, USA, 2007.

SHAFFER, David W. et al.Video games and the future of learning,2004. Disponível em:

<http://gise.rice.edu/documents/FutureOfLearning.pdf>.

VIANNA, Ysmar et al.Gamification, Inc: como reinventar empresas a partir de jogos. MJV Press, 2013.

XAVIER, Antonio Carlos S. Letramento digital e ensino. In: SANTOS,Carmi F.;MENDONÇA,Márcia. (Org.). Alfabetização e letramento: conceitos e relações.v. 1. Belo Horizonte: Autêntica, 2005. p. 1-9.

Submetido em: 20/09/2014 Aceito em: 25/11/2014

Title: Learning principles of electronic games: gamifying the language classes 